Artigo original

Hegemonia - Revista Eletrônica do Programa de Mestrado em Direitos Humanos, Cidadania e Violência/Ciência Política do Centro Universitário Unieuro

ISSN: 1809-1261

UNIEURO, Brasília, número 23, Janeiro a Junho de 2018, pp. 105-131.

Recebido em: 2/9/2017

Avaliado em: 13/11/2017

Aprovado em: 10/12/2017

\title{
TREINAMENTO, DESENVOLVIMENTO E EDUCAÇÃO EM INSTITUIÇÕES EDUCACIONAIS
}

Juliana Olinda Martins Pequeno ${ }^{1}$ e Iolanda Bezerra dos Santos Brandão ${ }^{2}$

RESUMO: Este artigo tem o objetivo de apresentar uma revisão teórica sobre as condições de evolução do treinamento e desenvolvimento profissional. Demonstrar através da pesquisa bibliográfica que a evolução da comunicação e dos processos de produção de bens e serviços obrigam as pessoas a se especializarem cada vez mais, levando a inteligência das pessoas a ser o principal capital gerido pelas instituições e que para tanto é preciso que se faça a gerencia das carreiras utilizando-se de técnicas modernas e disponíveis para todos. Demonstrar a evolução de Recursos Humanos para Gestão de Pessoas também nas Instituições de Ensino e as exigências para formação dos profissionais de Educação.

PALAVRAS-CHAVE: Educação. Treinamento. Instituições de Ensino

ABSTRACT: This article aims to present a theoretical review on the evolution of conditions of professional training and development. Demonstrate through bibliographic research that the evolution of communication and the evolution of the processes of production of goods and services force people to become more and more specialized in their professions, which leads to the fact that the intellectual capacity of people is the main capital managed by the institutions - for this, it is necessary to manage the careers using modern and accessible techniques. Demonstrate the evolution of Human Resources for

\footnotetext{
${ }^{1}$ Pedagoga e professora da Faculdade Projeção.

${ }^{2}$ Doutora em Psicologia Social e docente do Centro Universitário UNIEURO e da Faculdade Projeção.
} 
Artigo original

Hegemonia - Revista Eletrônica do Programa de Mestrado em Direitos Humanos, Cidadania e Violência/Ciência Política do Centro Universitário Unieuro

ISSN: 1809-1261

UNIEURO, Brasília, número 23, Janeiro a Junho de 2018, pp. 105-131.

People Management also in Educational Institutions and demonstrate the requirements for the training of education professionals.

KEYWORDS: Education, Training, Education Institutions.

INTRODUÇÃO

A sociedade mudou, e a tecnologia teve papel fundamental nas novas concepções de mundo que vieram a aparecer a partir destas, também, novas perspectivas.

Os impactos da conquista da ciência e da tecnologia levaram a sociedade, para uma realidade baseada cada vez mais na troca de valores simbólicos, mudando até os conceitos de trabalho, valorizando mais que tudo o conhecimento e a aprendizagem.

Neste contexto de mudanças diversas, as pessoas foram criando barreiras, margens e se fechando em espaços cada vez mais dominados por aqueles que têm poder, e neste caso, o poder do conhecimento.

Hoje as pessoas são consideradas bens para instituições sérias e estas por sua vez se preocupam em contribuir na evolução tanto pessoal quanto profissional destas pessoas na tentativa de inserir qualidade e eficácia à produção de bens e serviços mantendo o status desta instituição em alta no mercado.

Dada esta mudança estabelece-se a necessidade de abordagem deste processo de evolução e das novas condições para que o indivíduo seja efetivamente um ser social, em todas as esferas, mas que também evolua em suas formas de produção.

Com estas implicações inovadoras a educação sofreu e se a comunidade educacional está preparada para acompanhar esta evolução, incluindo pessoas e tornandoas "úteis" socialmente, tais pessoas tiveram que conviver com outro aspecto decorrente desta situação: o surgimento de novas formas de desenvolvimento da carreira dentro e fora das instituições de ensino.

O seguinte trabalho está dividido em dois capítulos. O capítulo primeiro trata do desenvolvimento dos recursos humanos em uma retrospectiva histórica, desde os tempos nas cavernas até a circulação no ciberespaço. 
Artigo original

Hegemonia - Revista Eletrônica do Programa de Mestrado em Direitos Humanos, Cidadania e Violência/Ciência Política do Centro Universitário Unieuro

ISSN: 1809-1261

UNIEURO, Brasília, número 23, Janeiro a Junho de 2018, pp. 105-131.

O segundo capítulo trata das transformações sócio-político-econômicas sofridas pelos indivíduos na trajetória evolutiva dos processos tecnológicos, sejam eles produtivos ou educacionais. A educação tem a função de incluir pessoas socialmente, investigar como estas pessoas estão preparadas para inclusão digital é uma condição para que se dê mais valor para o papel educacional e mais cuidado com o uso dos equipamentos tecnológicos.

1 - Recursos Humanos e Gestão de Pessoas

Neste primeiro capítulo abordamos aspectos relacionados ao contexto histórico e a evolução do trabalho na vida dos seres humanos. É notável que a evolução humana passa pela evolução do trabalho, pelo jeito que este transforma a natureza a sua volta na tentativa de inserir qualidade ao meio em que vive. Esta evolução se faz presente no uso de recursos tecnológicos como também nas condições que cercam as inúmeras carreiras profissionais.

1.1 A evolução dos recursos humanos para gestão de pessoas

É notável que a evolução humana passa pela evolução do trabalho, pelo jeito que este transforma a natureza a sua volta na tentativa de inserir qualidade ao meio em que vive. Esta evolução se faz presente no uso de recursos tecnológicos como também nas condições que cercam as inúmeras carreiras profissionais.

Observa-se que tudo evolui com as condições em que o homem precisa para viver melhor, para facilitar sua forma de produção e também nas condições em que ele realiza este trabalho.

Desde a antiguidade o homem já criava ferramentas que facilitassem a agricultura, depois foi criando máquinas poderosas que pudessem fazer para ele o trabalho insalubre ou que exigisse força e concentração.

Com as ferramentas e máquinas as formas de administrar o trabalho também evoluíram, o homem passou de escravo, a servo, a operário, a empregado, a funcionário, a colaborador, e hoje: associado ou talento de uma determinada empresa. 
Artigo original

Hegemonia - Revista Eletrônica do Programa de Mestrado em Direitos Humanos, Cidadania e Violência/Ciência Política do Centro Universitário Unieuro

ISSN: 1809-1261

UNIEURO, Brasília, número 23, Janeiro a Junho de 2018, pp. 105-131.

Esta área da administração dos meios de produção é conhecida como a de Recursos Humanos, que trata pessoas como parte importante na produção, e que ela também teve sua evolução própria.

Segundo TOLEDO (2003), os recursos humanos, atualmente, tem foco na democratização da organização do trabalho, que passa desde a participação dos funcionários em processos decisórios da empresa, até a criação de entidades, associações e instituições que tratem das negociações que envolvem esta relação.

Observa-se então que, no Brasil, desde a década de 1930, órgãos, leis, normas que facilitassem as regras para que as relações trabalhistas alcançassem seus objetivos foram sendo criadas, colocando-nos em posição privilegiada no ranking de organização do trabalho.

Acontece, porém que, as pessoas querem que seus direitos sejam cumpridos para que possam trabalhar em ambiente saudável, com mais qualidade de vida, saúde e segurança. Além de garantir a satisfação para exercerem determinadas funções com os benefícios sociais e melhores remunerações.

De outro lado as empresas, na sua maioria, preocupam-se com as condições de modo de produção, deixando de lado, ou para depois, as exigências das pessoas que nelas trabalham, e, de modo preocupante as empresas que se preocupam com todos estas condições, mas tem sérias dificuldades em fazer seus funcionários "vestirem a camisa da empresa" e não diminuem os índices de rotatividade.

Os seres humanos não conseguem exercer atividades das quais não gostem ou não se identifiquem, isso é notório desde a antiguidade. Esse é um dos motivos que levou o homem a desenvolver técnicas e ferramentas que facilitassem seu trabalho ou que dessem condições de salubridade para a realização do mesmo.

É preocupação, para manter ativo seu capital humano, fazer com que as pessoas tenham acesso de qualidade às técnicas, ferramentas e condições de salubridade no trabalho para participarem ativamente do crescimento da organização.

Com a evolução do trabalho, o homem também evoluiu individualmente, culturalmente e socialmente, de acordo com as exigências das transformações dos modos de produção. 
Artigo original

Hegemonia - Revista Eletrônica do Programa de Mestrado em Direitos Humanos, Cidadania e Violência/Ciência Política do Centro Universitário Unieuro

ISSN: 1809-1261

UNIEURO, Brasília, número 23, Janeiro a Junho de 2018, pp. 105-131.

Em 2000, MARRAS escreveu que a evolução do trabalho no século XX aconteceu em fases que receberam os nomes das suas próprias características. Na década de 1930, com a evolução do conceito dos cargos e de pessoas encarregadas de tratar os empregados das empresas, este profissional seguia comandando com rédeas curtas e de maneira metódica, mais preocupados em seguir as leis do que a conhecer o legado da administração de recursos humanos. Era a fase primária, conhecida como "legalista".

A partir dos anos de 1950 veio a fase chamada de "tecnicista", onde o termo recursos humanos começava a ser valorizado, pois seu administrador já tinha uma concepção diferenciada do legado e das expectativas das pessoas.

Esta fase levou organizações a considerar a opção de contratar profissionais melhor qualificados e preparados para trabalhar com equipes e gerencias de grupo. MARRAS (2000, p. 29 e 30) escreve: "O aspecto puramente legal da fase anterior passou a ser apenas uma das preocupações desse gerente, e não a principal. Entraram em cena os serviços administrativos e as práticas novas e de real valor para os empregados [...]".

$\mathrm{Na}$ fase seguinte, a "profissional", compreendida nas décadas de 1960 a 1980, ocorreu a conciliação das ARH com a formação cultural e acadêmica diferenciada do perfil do administrador de empresas.

Esse novo profissional tinha que ter, como escreve Marras (idem) visão geral e específica e focada em temas como marketing, produção, economia, psicologia e sociologia de forma multidisciplinar, bem como das relações de trabalho dentro e fora da empresa com seus clientes internos e externos.

O novo paradigma, imposto por estas mudanças fez fortalecer os sindicatos levando as organizações a voltarem seus olhos para as questões que cercam, até hoje, as relações de trabalho, principalmente as questões legais.

Por fim, a fase "estratégica", que teve seu ápice a partir dos anos de 1980. Nela o administrador de RH passa a fazer parte dos organogramas das organizações com papel estratégico, onde um diretor tem comprometimento com seus líderes, gerentes, coordenadores de pessoal, para inclusão da qualidade de vida no trabalho.

Sua importância é tamanha que é colocada como princípio básico a prestação do serviço ao servidor, por parte de seus pares hierárquicos, sobre isso disse LACOMBE 
Artigo original

Hegemonia - Revista Eletrônica do Programa de Mestrado em Direitos Humanos, Cidadania e Violência/Ciência Política do Centro Universitário Unieuro

ISSN: 1809-1261

UNIEURO, Brasília, número 23, Janeiro a Junho de 2018, pp. 105-131.

(2006, p. 19) : “... orientar e apoiar os gerentes e prestar-lhe serviços, mas a cada gerente cabe a administração dos seus recursos humanos [...], como também a sensibilização dos gerentes nos resultados."

Hoje, vários fatores têm incidência na $\mathrm{ARH}$, as principais são nas áreas econômica, tecnológica e mercadológica, assim vários aspectos ainda se contrapõem dentro deste importante processo das organizações.

LACOMBE (2006) e MARRAS (2000) concordam ao dizer que é contínua a tendência das organizações em manter um único organismo responsável pelo ARH, mas também são unânimes ao afirmarem que cada vez mais outros organismos e setores dentro de uma mesma empresa tem participado de medidas que auxiliam o processo de gerir as pessoas como o recrutamento, a seleção, o desenvolvimento e a manutenção dos mesmos.

Estas medidas favorecem a visão de que o ARH tem como objetivo principal a qualidade de vida no trabalho, a satisfação do cliente interno para satisfazer o cliente externo com aumento na qualidade e na produtividade.

O favorecimento se dá com a preocupação em administrar o capital humano que "é representado pelos profissionais do conhecimento"(LACOMBE, 2006, p.21) e que este capital marca a evolução da ARH de tal forma que a concepção do trabalho escravo ou insalubre ainda hoje possa existir.

Estamos, portanto,na era do "capital humano", desde 1994 o professor e escritor inglês Richard Crawford atenta para o fato de que o talento, a inteligência e o conhecimento são forças poderosíssimas, capazes de determinar o sucesso ou a falência de uma empresa, seja ele em qualquer área, como produto ou serviço.

Demonstra-nos ainda que estas "[...] pessoas educadas e habilitadas - como força dominante da economia.” (CRAWFORD, 1994, p.34), exercem papel tão fundamental capaz de mover uma empresa para frente ou para traz.

Em seus estudos sobre esta mudança de concepção, ainda na década de 1990, foi capaz de sinalizar que no futuro as instituições deverão preocupar-se, fundamentalmente, com “... seres humanos - seus corpos, habilidades e conhecimento - sendo parte de um estoque de capital do mundo.(IBIDEM)" 
Artigo original

Hegemonia - Revista Eletrônica do Programa de Mestrado em Direitos Humanos, Cidadania e Violência/Ciência Política do Centro Universitário Unieuro

ISSN: 1809-1261

UNIEURO, Brasília, número 23, Janeiro a Junho de 2018, pp. 105-131.

Isso não quer dizer que o mundo passa a ver os RH como mero capital, é muito mais do que isso, agora eles são o capital que move o conhecimento personificado, sem ele não há outro tipo de capital que resolve, ou seja, ele é essencial e faz parte da essência das organizações.

Onde há inteligência, há evolução e o ser humano capaz de desenvolver suas habilidades cognitivas e capaz de trazer produtividade e, conseqüentemente, lucro para as organizações.

O que significa que a empresa passa a se preocupar, cotidianamente com a formação, a atualização e, enfim com o treinamento de seus talentos.

Com as instituições de ensino houve uma mudança no aspecto geral, onde a instituição recebe, na atualidade, o status de empresa e somo tal também tem as mesmas preocupações com o seu capital humano.

No atual contexto social e econômico, poucas empresas têm exatamente as pessoas que desejam, fazendo exatamente aquilo que é necessário. Pode se tomar alguma providência a esse respeito ou simplesmente ignorar o assunto. Se ignorado, certamente aumentará a distância entre o que se precisa que as pessoas façam e o que elas realmente fazem.

Neste contexto o capital humano está em todas as áreas da empresa escola: professores, coordenadores, supervisores, monitores, auxiliares, porteiros, entre outros.

1.2 A sociedade tecnológica e o treinamento

No item anterior verificou-se a evolução do homem primitivo até a sociedade atual, em termos de produção, vejamos como ela funciona, nos dias de hoje e em que momentos o homem aprende.

Percebe-se então que o desenvolvimento tecnológico, cujo maior impulso ocorreu a partir da revolução industrial (Séc. XVIII) com o surgimento da eletricidade, do motor à explosão, da química orgânica e de tantos outros feitos da época, possibilitou a difusão da comunicação entre os povos. 
Artigo original

Hegemonia - Revista Eletrônica do Programa de Mestrado em Direitos Humanos, Cidadania e Violência/Ciência Política do Centro Universitário Unieuro

ISSN: 1809-1261

UNIEURO, Brasília, número 23, Janeiro a Junho de 2018, pp. 105-131.

A partir da segunda metade do Século XX, observa-se uma intensificação do desenvolvimento tecnológico o qual conduziu ao surgimento da "sociedade tecnológica". Tal sociedade caracteriza-se, sobretudo, pelo processo de geração de conhecimentos, de processamento de informação e de comunicação de símbolos.

Além disso, a "sociedade tecnológica" tem como característica marcante, a velocidade na troca de informações. Tal fato faz com que, por exemplo, o capital especulativo seja gerenciado vinte quatro horas por dia, ou seja, as transações financeiras ocorrem em tempo real. Tudo isso só é possível em função das novas tecnologias de comunicação e informação.

KENSKI (2003, p.26) analisa este novo contexto e sua nova maneira de pensar da seguinte forma:

... Cria-se, assim, uma lógica de consumo e a produção de novos hábitos que dão origem à necessidade de adaptabilidade constante das pessoas ao inusitado, ao 'devir incerto, que em nenhum momento se apresenta como libertação, autonomia, ou ampliação da visão crítica da sociedade.

Pode se verificar assim, que o homem segue sendo escravo destas novas regras, até as pautas de discussão, análise e conclusão diárias são estabelecidas por outros meios, principalmente pela mídia.

Perde-se o poder sobre as próprias decisões de forma gradativa, nossos pensamentos, opiniões e até a nossa subjetividade vão sendo manipuladas e novas regras são estabelecidas.

Torna-se determinante que através da educação ter-se-á condições de compreender e de se colocar na sociedade contemporânea, enquanto cidadãos partícipes e responsáveis. Deve-se então compreender as novas tecnologias como elementos mediadores para a construção de uma nova representação da sociedade.

A construção desta sociedade compõem-se do estudo interdisciplinar, multidisciplinar e ainda transdisciplinar de filosofia, antropologia, sociologia, psicologia e 
Artigo original

Hegemonia - Revista Eletrônica do Programa de Mestrado em Direitos Humanos, Cidadania e Violência/Ciência Política do Centro Universitário Unieuro

ISSN: 1809-1261

UNIEURO, Brasília, número 23, Janeiro a Junho de 2018, pp. 105-131.

educação, no intuito de desvendar os caminhos que levam o homem ao conhecimento. Partimos de algumas premissas básicas:

1. Só se obtém conhecimento através da aprendizagem;

2. Aprendemos todos os dias, todas as horas e em qualquer lugar;

Aprendizagem é uma característica primordial dos seres humanos, se ele não aprende é isolado da sociedade, portanto ele é também constante e maleável, exige orientação e planejamento.

OLIVEIRA (2004) diz que a educação é uma das atividades básicas de todas as sociedades humanas, pois as pessoas precisam dela para sobreviver, da transmissão do conhecimento adquirido de um ao outro. E se o homem aprende sempre quanto conhecimento ele pode dispor para sua sobrevivência com qualidade, aplicado ao capital das empresas.

O papel do treinamento e desenvolvimento é usar esta visão diversificada deste ser humano feitos de antropologias, sociologias, psicologias e aproveitar o potencial de cada de forma a que ele se desenvolva cognitivamente e agregue conhecimento e dissemine valores dentro das instituições onde trabalha.

No próximo item trataremos dos conceitos e das condições do treinamento e desenvolvimento dos recursos humanos nas organizações em geral.

\subsection{Treinamento e Desenvolvimento dos Recursos Humanos}

No atual contexto social e econômico, poucas empresas têm exatamente as pessoas que desejam, fazendo exatamente aquilo que é necessário. Pode se tomar alguma providência a esse respeito ou simplesmente ignorar o assunto. Se ignorado, certamente aumentará a distância entre o que se precisa que as pessoas façam e o que elas realmente fazem.

Da mesma forma, somente algumas pessoas estão exatamente no cargo que gostariam, fazendo as coisas que sabem fazer melhor. Se você ignorar isto, pode perder sua força de trabalho, ou acabar ficando com pessoas desinteressadas e entediadas na hora em 
Artigo original

Hegemonia - Revista Eletrônica do Programa de Mestrado em Direitos Humanos, Cidadania e Violência/Ciência Política do Centro Universitário Unieuro

ISSN: 1809-1261

UNIEURO, Brasília, número 23, Janeiro a Junho de 2018, pp. 105-131.

que mais precisar delas para adotar novas idéias ou fazer mudanças. Muita gente deixa o trabalho por não ser treinada ou desenvolvida.

Desenvolver pessoas não é apenas desenvolver novas habilidades; é o desenvolvimento da capacidade e da vontade de se adaptar. Em função disto, as empresas que ativamente procuram desenvolver seu pessoal sobrevivem e prosperam. As que não o fazem, normalmente são as primeiras a se dar mal.

O Objetivo, então do desenvolvimento das pessoas nas empresas é estimular, provocar e promover a evolução destas pessoas e da própria organização. DUTRA (2006, p.101) define o desenvolvimento da pessoa como "capacidade para assumir atribuições e responsabilidades em níveis crescentes de complexidade", ou seja, preparar pessoas para que elas possam evoluir em suas funções e cargos, fazendo evoluir também a própria organização. ARAUJO (2006, p 92), inicia a definição e conceito sobre este tema provocando reflexão sobre T\&D (Treinamento e Desenvolvimento), quando vários autores dizem ser termos distintos e com objetivos totalmente diferenciados. Uns dizem que o treinamento é mais importante que o desenvolvimento, outros como LIMA (2004): "treinamento é um investimento empresarial destinado a capacitar uma equipe (Apud ARAUJO, 2006, p.32)" e outros ainda que o foco do treinamento e do desenvolvimento é a aprendizagem.

Para ele, seja qual for o foco ou a definição, “o treinamento e o desenvolvimento serão fundamentais para a crescente busca da excelência nos negócios.(Idem, p.94)”. Os dois compõem um processo de aprendizagem ora com o objetivo de preparar as pessoas para determinadas tarefas, ora focado no desenvolvimento intelectual bem como a evolução de habilidades e competências.

O processo de planejamento do treinamento e desenvolvimento de pessoas num empresa passa pela avaliação da aplicação, por questionamentos do tipo: para quê, porquê e como. Segundo ARAÚJO (2006) alguns aspectos podem ser observados, já que aprendemos todo o tempo, mas nas organizações torna-se necessário foco nos aspectos abaixo listados, para que a ela alcance seus objetivos.

$>\quad$ Identificação de objetivos no processo.

Identificação de problemas ligados à produtividade, retrabalho, refugo, etc. 
Artigo original

Hegemonia - Revista Eletrônica do Programa de Mestrado em Direitos Humanos, Cidadania e Violência/Ciência Política do Centro Universitário Unieuro

ISSN: 1809-1261

UNIEURO, Brasília, número 23, Janeiro a Junho de 2018, pp. 105-131.

$>\quad$ Problemas de comunicação, ou uma normalização dos termos utilizados na produção para que não haja equívocos.

$>\quad$ Ascensão profissional e a migrações dentro da empresa.

$>\quad$ Processo de informatização e atualizações dos modos de produção.

$>\quad$ Programas de training visando diminuir a distância entre a teoria e a prática.

$>\quad$ O tipo de atividade exercida pela organização e os processos diferenciados de produção.

O comprometimento dos altos níveis hierárquicos com o processo de T\&D.

$>\quad$ Saber o ponto de partida e aonde se quer chegar aos processos de T\&D, fazendo com que este seja positivo.

Hoje, o que se vê é que a maioria das empresas só utiliza o Treinamento, com o foco de adequar este novo funcionário à cultura da empresa, seu modo de produção, suas certificações e para a tarefa que ela irá desenvolver. Poucas empresas preocupam-se com outras finalidades, de possível alcance através da T\&D, como a mudança de atitudes; a adaptação das pessoas para os processos de informatização e/ou modernização; o preparo para o remanejamento; a cultura de disseminação da informação; a redução dos custos em busca dos objetivos da empresa; o desenvolvimento pessoal e profissional; entre outros.

Existem várias formas de realizar programas de $\mathrm{T} \& \mathrm{D}$, principalmente usando as novas tecnologias da informação disponíveis à maioria das organizações, que podem usar desde o telefone, até os recursos da Internet e o ambiente do ciberespaço, existem, afinal o ensino à distância. ARAUJO (2006, p.100) sugere que:

... com a necessidade por uma ação competente em termos de treinamento e desenvolvimento, é natural que os gestores de pessoas se utilizassem do crescimento exponencial da tecnologia da informação e de novas tecnologias que estão surgindo no mundo dos negócios. 
Artigo original

Hegemonia - Revista Eletrônica do Programa de Mestrado em Direitos Humanos, Cidadania e Violência/Ciência Política do Centro Universitário Unieuro

ISSN: 1809-1261

UNIEURO, Brasília, número 23, Janeiro a Junho de 2018, pp. 105-131.

Quando as empresas aproveitam seu potencial tecnológico, necessário para que ela continue a existir, o processo de T\&D se torna mais barato e eficaz. Alguns exemplos de utilização destas novas tecnologias são:

Workshop, ou as famosas oficinas, que pode ser ministrada por um especialista prático, alguém que já conhece o assunto.

$>\quad$ Coachig, pessoas que têm experiência com as práticas do trabalho e conhecimento da carreira, colaborando diretamente com os novatos.

$>\quad$ Mentoring, pessoas que têm experiências sobre as tarefas a serem executadas e podem fazer o papel de preparo e divulgação da cultura empresarial.

$>$ Teleconferência e videoconferências, usando recursos de telefone, Internet, computadores e televisão.

$>\quad$ Internet e Intranet, as redes de comunicação mais utilizadas: Internet para o meio externo e Intranet para o meio interno.

Universidade Corporativa, que oferece meio de crescimento profissional a partir da prática diária do funcionário.

Educação à distância, permite que se alcance níveis educacionais utilizando recursos tecnológicos dentro da própria organização.

O importante é notar que as organizações tem que ter planejado as inúmeras vantagens do $\mathrm{T} \& \mathrm{D}$, incluindo a motivação para o trabalho, tão reforçada quando o funcionário vê possibilidades de ascensão, seja ela profissional ou pessoal.

A organização e o planejamento do T\&D na empresa, deve ser realizado por profissionais que tenham conhecimento da própria organização, das condições em que se dá o desenvolvimento profissional e pessoal para o funcionário e para a organização. 
Artigo original

Hegemonia - Revista Eletrônica do Programa de Mestrado em Direitos Humanos, Cidadania e Violência/Ciência Política do Centro Universitário Unieuro

ISSN: 1809-1261

UNIEURO, Brasília, número 23, Janeiro a Junho de 2018, pp. 105-131.

2- Gestão de Pessoas e o Profissional de Educação

No capítulo a seguir serão abordados disposições atuais sobre este contexto o capital humano está em todas as áreas da empresa escola: professores, coordenadores, supervisores, monitores, auxiliares, porteiros, entre outros, com o objetivo de fazer um comparativo com sua evolução e a evolução do profissional de serviços.

\subsection{O Desenvolvimento Profissional na Educação}

Neste contexto o capital humano está em todas as áreas da empresa escola: professores, coordenadores, supervisores, monitores, auxiliares, porteiros, entre outros.

Observamos que com freqüência as instituições de ensino não tem tratado a progressão profissional de seu corpo docente de acordo com as novas demandas da gestão de pessoas, mesmo porque outras instituições comerciais relutam em perceber que o seu maior patrimônio é a inteligência desenvolvida de seus funcionários.

Dentro destas novas perspectivas podemos então entender porque se confundem os conceitos de treinamento, desenvolvimento, formação profissional, formação continuada e educação corporativa, ou quando se fundem e gestores imaginam que dado treinamento constantes estão também contribuindo para a formação de seus funcionários, contribuindo para o seu desenvolvimento profissional e com o foco na evolução institucional.

Faremos então um estudo sobre os diversos conceitos para que entendamos melhor os aspectos que envolvem a educação profissional e corporativa, procurando entender como ela pode colaborar em condições de processos para o desenvolvimento de pessoas também nas organizações de ensino. 
Artigo original

Hegemonia - Revista Eletrônica do Programa de Mestrado em Direitos Humanos, Cidadania e Violência/Ciência Política do Centro Universitário Unieuro

ISSN: 1809-1261

UNIEURO, Brasília, número 23, Janeiro a Junho de 2018, pp. 105-131.

\subsubsection{Formação Profissional}

Segundo as autoras MOURÃO e PUENTE-PALACIOS (2006, p.41), no artigo Formação Profissional, o mercado de trabalho vem mudando em vários aspectos e ganhando novas condições para que as pessoas sejam capazes de se identificar com as tarefas que realizam, ou seja para que aconteça o papel social do trabalho, que é de cumprimento das necessidades dos seres humanos.

Sendo assim, completam as autoras, torna-se necessário entender os conceitos de treinamento e formação profissional no Brasil, já que temos um contexto diferenciado do mercado de trabalho.

Neste sentido com relação a formação continuada devem ser considerados alguns aspectos como a natureza processual de cada profissão, a ligação que esta formação tem com o sistema educacional, e como se dá o seu desenvolvimento nas escolas e nas instituições comerciais, e por fim quais o conhecimentos teóricos e práticos, devem ou podem ser oferecidos aos formandos. Assim sua meta maior deverá ser a inclusão do indivíduo na sociedade através do trabalho.

Segundo as autoras a "formação profissional deverá permitir ao indivíduo adquirir e desenvolver conhecimentos teórico, técnico e operacional relacionados à produção de bens e serviços." Para tanto é necessário que haja acompanhamento constante e incisivo no sentido de promover avaliações, formativas, com metas, impacto e processos, com foco na melhoria, de forma objetiva e colaborativa.

A formação profissional compreende o ensino profissional os curso de formação técnicas em nível de ensino médio, os cursos técnicos de nível superior, as licenciaturas e bacharelados de curta e longa duração, as certificações processuais e os MBA, as pósgraduações stricto senso, entre outros. 
Artigo original

Hegemonia - Revista Eletrônica do Programa de Mestrado em Direitos Humanos, Cidadania e Violência/Ciência Política do Centro Universitário Unieuro

ISSN: 1809-1261

UNIEURO, Brasília, número 23, Janeiro a Junho de 2018, pp. 105-131.

Espera-se muito hoje que os indivíduos já cheguem às instituições com alguma formação profissional, normalmente exige-se tanto a teórica quanto a prática na função que irá exercer.

\subsubsection{Formação Continuada}

Entende-se que a formação continuada é um processo fundamental pelo qual todos os profissionais comprometidos com suas funções institucionais deve passar, em todas as áreas de mercado seja de produtos ou de serviços.

A Formação continuada permitirá que a progressão de carreira aconteça de forma justa e democrática e segundo TOLEDO (2003), quando existem os planos de cargos e salários eles se baseiam nas progressões que as pessoas podem atingir a partir de conhecimentos adquiridos dentro ou fora da instituição, mas com foco nos processos necessários para que esta evolua e cresça.

Pensemos então em uma instituição educacional, onde o próprio foco de serviço é o desenvolvimento educacional, é a evolução cognitiva. Esta preocupação está demonstrada nas metas do MEC para o próximo ano de 2010, cujo o foco principal será a formação de professores. Segundo o ministro da Educação, Fernando Haddad, “... a elevação da qualidade de ensino passa por oferecer ao docente amplas oportunidades de educação continuada."

De acordo com o que diz Guillhermino Figueira Neto, diretor geral do PUERI DOMUS ESCOLAS ASSOCIADAS, apesar de sua importância em todas as áreas de conhecimento, a formação continuada é de fundamental importância para a evolução da educação, mais principalmente para a valorização do trabalho profissional de educação, pois permite o aumento de oportunidades.

Observamos então que a evolução da escola, como instituição comercial e prestadora de serviços fundamentais, passa pela formação continuada de seus profissionais em todos os níveis de hierarquia. 
Artigo original

Hegemonia - Revista Eletrônica do Programa de Mestrado em Direitos Humanos, Cidadania e Violência/Ciência Política do Centro Universitário Unieuro

ISSN: 1809-1261

UNIEURO, Brasília, número 23, Janeiro a Junho de 2018, pp. 105-131.

Compreendemos que a formação continuada é um conjunto de ações de atualização que envolvem leitura, estudo, treinamento e que levem ao desenvolvimento do indivíduo e à sua progressão profissional. Portanto o TD\&E fazem parte desta formação permitindo o crescimento intelectual do capital humano de uma instituição.

Segundo VARGAS e ABBAD (2006, p. 151), o treinamento, desenvolvimento e educção nas instituições está diretamente ligado à formação continuada, já que " a aprendizagem humana pode se dar de várias maneiras (...) e que nem todas as situações que geram aprendizagem são ações formais de treinamento...”, mas com certeza tem sentido de formação.

Podemos então caracterizar algumas situações em que a formação continuada e a TD\&E estão presentes no trabalho, quanto há:

- Disseminação de informações como forma de indução à aprendizagem;

- Instrução na transmissão de conhecimentos ligados a determinados processos;

- Cursos, oficinas e treinamentos voltados para a melhoria do trabalho e sua produtividade;

- Desenvolvimento pessoal permitindo a progressão de cargos e funções, sempre com o objetivo de aumento de capital individual;

Entendemos que toda forma de aprender dentro do trabalho, seja do simples conversar com os colegas, até os cursos mais complexos com muitas horas de duração contribuem para a formação continuada dos indivíduos e são de fundamental importância para os processos evolutivos das instituições educacionais.

\subsubsection{Educação Corporativa}

De acordo com os dicionários da língua portuguesa a educação é a forma mais abrangente de aprendizagem dos indivíduos, pois este conceito permeia o desenvolvimento 
Artigo original

Hegemonia - Revista Eletrônica do Programa de Mestrado em Direitos Humanos, Cidadania e Violência/Ciência Política do Centro Universitário Unieuro

ISSN: 1809-1261

UNIEURO, Brasília, número 23, Janeiro a Junho de 2018, pp. 105-131.

cognitivo, emocional, social e profissional. Os mais vários conceitos levam a conclusão de que um indivíduo precisa se educar, ou ser educado para que sua inclusão social e seu desenvolvimento ocorra.

A educação continuada então é um termo que envolve redundâncias, já que nos educamos automaticamente continuamente sobre os outros e sobre nós mesmos. Isso mantém as pessoas em constante evolução e com a sua presença garantida no mercado profissional e consequentemente na sociedade.

Podemos dizer que é a forma que o indivíduo tem de atender as exigências sociais. As autoras VARGAS e ABBAD (2006, p. 149) completam: “... bem além de uma adaptação necessárias às exigências do mundo do trabalho, é a condição para um domínio mais perfeito dos ritmos e dos tempos da pessoa humana. (APUD DELORS, 2002).”.

Notamos que a partir desta evolução da educação nas instituições, estas mesmas foram encontrando formas para que seu capital humano crescesse na tentativa de melhorar e evoluir no mercado. Hoje podemos observar empresas do ramo privado onde são divulgados a quantidade de funcionários com um determinado tipo de formação. E por outro lado empresar de ramo público divulgando inovações elaboradas por pessoal próprio.

Para que chegássemos a estas novas perspectivas muitas instituições desenvolveram novas formas de progressões de cargos e salários e até mesmo de formação especializadas criando, já nas décadas de 1990 a educação corporativa, totalmente voltada para a evolução de seu capital humano.

A educação corporativa envolve modelos de treinamento pontuais para os empregados em todos o níveis de uma instituição, ou seja desde empregados do nível operacional até para os executivos com programa educacionais mais avançados.

A evolução do TD\&E foi o que propiciou os programas de formação das empresas aos nível de educação corporativa envolvendo curso em EAD, EJA e universidade corporativa, como projetos que compreendem os níveis estratégicos das instituições. Essa revolução tecnológica ocorrida no século passado na área de recursos humanos é que preocupada em desenvolver habilidade dos empregados é que passaram a fazer parte da organização das empresas e que levou os crescimento da educação corporativa. 
Artigo original

Hegemonia - Revista Eletrônica do Programa de Mestrado em Direitos Humanos, Cidadania e Violência/Ciência Política do Centro Universitário Unieuro

ISSN: 1809-1261

UNIEURO, Brasília, número 23, Janeiro a Junho de 2018, pp. 105-131.

Conforme dizem as autoras VARGAS e ABBAD (2006, p. 151), os princípios da educação corporativa compreendem a competitividade onde estejam comprometidos com o seu desenvolvimento pessoal e o da insituição, a perpetuidade fazendo parte da cultura organizacional, a conectividade juntando todos os níveis hierárquicos, a disponibilidade que é a educação em qualquer hora e lugar, a cidadania na formação completa do indivíduo, as parcerias internas e externas que permitam a evolução conjunta profissional e do trabalho, a sustentabilidade onde sejam possíveis a evolução institucionais e do próprio negócio.

\subsection{Treinamento e sua Devolutiva}

Escreve-nos ainda ARAUJO (2006, p. 116) que hoje treinar e desenvolver profissionais, é muito mais presente e comum à qualquer indivíduo, pois vivemos sempre aprendendo e houveram evoluções, inclusive nas formas de aprendizagem, por isso “...

treinar e desenvolver pessoas sofreu aperfeiçoamento e entendemos que tornou a atividade fundamental para a busca da excelência organizacional."

Para tanto o autor demonstra como deve ser o TD\&E e a educação corporativa através na delimitação das seguintes dimensões de organização:

- O foco deve ser nas relações interpessoais.

- O conteúdos devem objetivar o desenvolvimento de atividades coletivas e intergrupais.

- As metas devem alcançar todos os níveis hierárquicos e envolver de gestores a operadores.

- O processo de aprendizagem tem que ter como parâmetros o cognitivo, o racional, o emocional e o motivacional dos indivíduos.

- Os objetivos são adaptados/mudanças e conscientização.

- A organização deve ter uma percepção social mais ampla e completa. 
Artigo original

Hegemonia - Revista Eletrônica do Programa de Mestrado em Direitos Humanos, Cidadania e Violência/Ciência Política do Centro Universitário Unieuro

ISSN: 1809-1261

UNIEURO, Brasília, número 23, Janeiro a Junho de 2018, pp. 105-131.

Neste sentido um plano de educação corporativa é fundamental e deve ser feito antecipadamente envolvendo todas as condições necessárias para sua continuidade com abrangência nos aspectos que regem uma instituição.

Dentro dos aspectos institucionais a serem observados podemos citar, a missão, a cultura organizacional, o desenvolvimento estratégico, a descentralização, a competitividade, a flexibilidade, a rede e tudo isso preocupando-se com o principal: os seres humanos que dão suporte a ela.

Segundo DUTRA (2006), tão importante quanto o planejamento é a avaliação horizontal e vertical, sendo feita durante todo o processo, com continuidade e acompanhamento. Deve-se partir de uma avaliação prévia para a elaboração do próprio plano, as avaliações de acompanhamento e a avaliação final para a verificação dos objetivos e das mudanças que deverão ser realizadas.

A avaliação prévia ou inicial permitirá fazer ou criar condições para que o treinamento tenha como meta o desenvolvimento profissional e emocional na evolução do indivíduo e da instituição. Este tipo de avaliação levará ao planejamento específico e detalhado do que deve ser feito, respeitando os vários aspectos e os planos de cargos e salários.

O acompanhamento do plano permitirá medir as condições necessárias ao seu funcionamento que poderão ser medidas através de folha de freqüência, trabalhos e notas dos formandos.

A avaliação final deve ter como objetivo o próprio planejamento e suas condições de realização, onde os focos poder ser o ambiente, os conteúdos, professores, instrutores e formadores. Esta se dá de forma devolutiva, o formado ajudará nesta avaliação no sentido que elaborar novos processos e procedimentos em suas próprias funções. Neste caso ele também irá colaborar na evolução da própria educação corporativa.

Quando usamos o termo: devolutiva, estamos traduzindo o termo 'feed back' que é muito utilizado no meio de gestão de pessoas, para demonstrar as reações das pessoas a partir de determinadas situações, ou de uma condição específica.

A devolutiva permite que o indivíduo que realizou a formação possa dizer o que será realmente útil no dia-a-dia de seu trabalho, como será sua interpretação dos métodos 
Artigo original

Hegemonia - Revista Eletrônica do Programa de Mestrado em Direitos Humanos, Cidadania e Violência/Ciência Política do Centro Universitário Unieuro

ISSN: 1809-1261

UNIEURO, Brasília, número 23, Janeiro a Junho de 2018, pp. 105-131.

que aprendeu, ou seja, identificar o que vai, ou não vai servir para complementar e melhorar sua produção de bens e serviços.

Podemos então pensar sobre a importância da avaliação da TD\&E, pois segundo BORGES-ANDRADE (2006, p.343), permite a observação de resultados imediatos voltados para a reação e aprendizagem imediata dos formandos, como os efeitos à longo prazo, onde podemos citar o comportamento diante da própria função ou cargo, as mudanças na organização do trabalho e por fim as de valor final relacionadas aos valores sociais e econômicos a própria instituição.

Assim sendo BORGES-ANDRADE (2006, p.346), nos sugere o Modelo de Avaliação Integrado e Somativo (MAIS) em TD\&E, que permite a avaliação dos eventos ou de um programa de formação a partir de métodos de formulações de questões e levantamento de informações relativas a operacionalização e execução da educação corporativa.

Este autor ainda nos leva a considerar a seguinte questão: Para quê avalia TD\&E, a educação corporativa?

A resposta:

[...] sugere a hierarquia de objetivos de avaliação, que vai da razão mais elementar à razão mais comlexa: obter controle, fazer retroalimentação, tomar decisões, fazer TD\&E funcionar e torná-lo extremamente válido. O uso do MAIS (Modelo de Avaliação Integrado e Somativo) pode permitir o alcance desses objetivos. Cabe aos que o utilizam a decisão sobre como e onde chegar. (Apud HAMBLIN, 1978).

Precisamos ter em mente que qualquer avaliação deve sempre envolver julgamento de valor, requer seu próprio planejamento, suas características devem ser determinadas pelos princípios do plano, deve ser oportunidade para construir conhecimento e como premissas para mudanças nos planos de TD\&E. 
Artigo original

Hegemonia - Revista Eletrônica do Programa de Mestrado em Direitos Humanos, Cidadania e Violência/Ciência Política do Centro Universitário Unieuro

ISSN: 1809-1261

UNIEURO, Brasília, número 23, Janeiro a Junho de 2018, pp. 105-131.

A devolutiva dos formandos e formadores deve compor a avaliação e suas respostas e condições devem fazer parte deste novo contexto criado a partir da educação corporativa.

\subsection{A Instituição de Ensino e o Treinamento e Desenvolvimento}

Pensar que o treinamento e o desenvolvimento dizem respeito a todo tipo de instituição comercial já é repetir a lógica, mas pode-se observar que as instituições de ensino, sejam público ou privadas, só passaram a se preocupar com tal situação nos últimos anos, apesar de que na década de 1990 o estudioso José Carlos Libâneo já alertava para este fato.

Podemos então citar suas obras em que este dilema foi abordado insistentemente como: Adeus Professor, Adeus Professora? Novas exigências educacionais e profissão docente. e Democratização da Escola Pública: A pedagogia crítico-social dos conteúdos, entre outros.

O autor nos leva primeiro a refletir sobre as várias mudanças tecnológicas ocorridas no exercício da função de ensinar, relativas principalmente ao objetivo da educação em si, que é o de incluir socialmente os indivíduos.

Logo no primeiro exemplar acima citado podemos verificar um capítulo inteiro sobre a qualidade de ensino e a relação que esta tem com a formação inicial e continuada dos professores. No terceiro capítulo Libâneo relata as mudanças pedagógico-currículares, atitudes que o professor deve levar em consideração para que ele e sua profissão evoluam, e como e qual é o papel deste corpo docente com relação a reorganização das formas atuais de formação continuada de professores.

Quando se diz que o autor escreveu seus textos na década de 1990, imagina-se logo que esta literatura já foi discutida e debatida o suficiente, mas podemos verificar o quanto atual as discussões propostas ainda estão em vigência quando diz:

... Os fatos contemporâneos ligados aos avanços científicos e tecnológicos, à globalização da sociedade, à mudança dos processos 
Artigo original

Hegemonia - Revista Eletrônica do Programa de Mestrado em Direitos Humanos, Cidadania e Violência/Ciência Política do Centro Universitário Unieuro

ISSN: 1809-1261

UNIEURO, Brasília, número 23, Janeiro a Junho de 2018, pp. 105-131.

de produção e suas consequências na educação, trazem novas exigências à formação de professores, agregadas às que já se punham até este momento. Este processo recente, configurando uma virada no interior do modo de produção capitalista, ao mesmo tempo que traz benefícios à humanidade pelo crescente avanço científico e tecnológico é, também, fator de ampliação da exclusão social. (...) O professorado, diante das novas realidades e da complexidade de saberes envolvidos presentemente na sua formação profissional, precisaria de formação teórica mais aprofundada, capacidade operativa nas exigências da profissão, propósitos éticos para lidar com a diversidade cultural e a diferença(...). (LIBANEO, 2003, p. 76 e 77)

Observa-se que o autor coloca todas as condições que continuamos evidenciando atualmente, ligadas aos avanços tecnológicos e as condições econômicas que regem as sociedades atuais, gerando novos tipos de exclusão de seres humanos. Abordando aspectos que demonstram as condições em que se encontram, ainda hoje, as instituições de ensino públicas sem que existam programas governamentais voltados para o desenvolvimento profissional desta classe de trabalhadores.

Pensando nos fatores citados pelo autor como: “...formação teórica mais aprofundada(...) e a capacidade operativa (...)", relacionada à profissionalização específica como uma linha de aprofundamento, citando como exemplo um professor alfabetizador que durante a sua vida profissional faz vários treinamentos, cursos ou formações que o levem a se atualizar, modernizar seu conhecimento e seus métodos levando-o a trabalhar cada vez melhor e forma mais eficaz.

Libâneo então defende processos onde todo o corpo docente tenha em sua formação inicial mais contato com as questões práticas, sem que as questões teóricas sejam menosprezadas e propõe novos formas de que manter uma formação continuada e eficaz a partir de políticas públicas eficazes e de uso das técnicas que a própria sociedade desenvolveu a partir do uso das novas tecnologias e sua relação com a educação. 
Artigo original

Hegemonia - Revista Eletrônica do Programa de Mestrado em Direitos Humanos, Cidadania e Violência/Ciência Política do Centro Universitário Unieuro

ISSN: 1809-1261

UNIEURO, Brasília, número 23, Janeiro a Junho de 2018, pp. 105-131.

Lembrando que a prática é fundamental, bem como a participação deste corpo docente com as formas e métodos que levaram estes próprios ao desenvolvimento de suas habilidades e competências individuais em prol do desenvolvimento completo de seus clientes (os estudantes).

Verifica-se então que para as instituições de ensino particulares o problema se agrava consideravelmente quando deixam que o desenvolvimento profissional aconteça diretamente por conta do próprio profissional sem incentivo ou orientação para este processo ocorra tendo como objetivo o crescimento na função que exerce. Na maioria das vezes as formações planejadas e patrocinadas pela maioria das instituições de ensino particular são aquelas que dizem respeito aos aspectos operacionais de sua profissão, como o uso de uma metodologia de ensino específico ou aos sistemas de ensino utilizados pelas mesmas.

Afirma-se então que o treinamento e o desenvolvimento das pessoas nas instituições trazem benefícios conjuntos, tanto em qualidade na produção como no produto final, levando o profissional a alcançar qualidade de vida e assim a satisfação profissional.

No caso das instituições de ensino as condições de treinamento e de desenvolvimento de seu corpo docente e da equipe gestora tem maior influência no serviço por ela prestado, o que pode inclusive incidir diretamente no desenvolvimento de seu cliente final.

Afinal tanto a instituição educacional quanto este profissional tem responsabilidades sociais de inclusão de seus estudantes e o faz através da própria educação.

Verificamos, na leitura de todos os capítulos anteriores que o homem evolui todos os dias bem como os bens e serviços que lhe permitem maior qualidade de vida.

Observa-se também que a medida que estes bens e serviços evoluem as pessoas necessitam cada vez mais se educar e se especializar para lhe das com as evoluções de técnicas no trabalho. 
Artigo original

Hegemonia - Revista Eletrônica do Programa de Mestrado em Direitos Humanos, Cidadania e Violência/Ciência Política do Centro Universitário Unieuro

ISSN: 1809-1261

UNIEURO, Brasília, número 23, Janeiro a Junho de 2018, pp. 105-131.

O que também ocorre no campo profissional de todos os tipos de instituições é que a gestão tem que prever não só os avanços tecnológicos mas também como seus geridos se comportaram no manejo de tais tecnologias.

Para tanto tão importante quando gerir os processo de produção é de fundamental importância a gerencia das pessoas e de suas carreiras, ou seja de seu desenvolvimento pessoal e profissional dentro das instituições de ensino.

Nota-se que quando usamos a palavra gerencia, estamos nos referindo a todos os processo que levam a sua eficácia como plano, acompanhamento, execução, avaliação, replanejamento e assim por diante. Também é necessário que este processo funcione no treinamento e desenvolvimento das pessoas dentro de uma organização. O desenvolvimento do profissional de educação tem que passar pela análise do próprio profissional, orientado por um mentor ou gestor de carreira que saiba aproveitar o melhor de cada um fazendo com que a sua evolução também seja o melhor para a instituição.

Fazer o caminho completo, cumprindo as exigências que cada processo impõem é que levaram uma instituição de ensino a permanecer no mercado prestando serviços de qualidade e garantido a fidelidade e a participação leal de sua equipe pedagógica.

\section{REFERÊNCIAS}

ARAUJO, Luis Cesar G. de. Gestão de Pessoas. - São Paulo: Atlas, 2006.

BOHLANDER, George W; SNELL, Scott; SHERMAN, Arthur. Administração de recursos humanos. Maria Lúcia G. Leite Rosa (Trad.). São Paulo: Pioneira Thomson Learning, 2005.

BORGES-ANDRADE, J e E; ABBAD, G. S \& MOURÃO, L (Org.): Treinamento, Desenvolvimento e Educação em organizações e trabalho: fundamentos para gestão de pessoas. Porto Alegre: Artmed, 2006.

CHIAVENATO, Idalberto. Administração de Recursos Humanos - 6. ed. São Paulo: Atlas, 2007. 
Artigo original

Hegemonia - Revista Eletrônica do Programa de Mestrado em Direitos Humanos, Cidadania e Violência/Ciência Política do Centro Universitário Unieuro

ISSN: 1809-1261

UNIEURO, Brasília, número 23, Janeiro a Junho de 2018, pp. 105-131.

CHIAVENATO, Idalberto. Recursos Humanos: o capital humano das organizações -8. ed. São Paulo: Atlas, 2006.

CRAWFORD, Richard. $\mathrm{Na}$ era do capital humano: o talento, a inteligência e o conhecimento como forças econômicas, seu impacto nas empresas e nas decisões de investimento. 1. ed. São Paulo: Atlas, 1994.

DANIEL, John. Educação e tecnologia num mundo globalizado. Brasília: UNESCO, 2003.

DAVEL, Eduardo; VASCONCELOS, João (Orgs). Recursos humanos e subjetividade - 4. ed. Petrópolis: Vozes, 2002.

DUTRA, Joel Souza. Gestão de Pessoas: modelo, processos, tendências e perspectivas. - 1 ed. -5 reimpr. São Paulo: Atlas, 2006.

CRAWFORD, Richard. $\mathrm{Na}$ era do capital humano: o talento, a inteligência e o conhecimento como forças econômicas, seu impacto nas empresas e nas decisões de investimento. 1. ed. São Paulo: Atlas, 1994.

DANIEL, John. Educação e tecnologia num mundo globalizado. Brasília: UNESCO, 2003.

DAVEL, Eduardo; VASCONCELOS, João (Orgs). Recursos humanos e subjetividade - 4. ed. Petrópolis: Vozes, 2002.

DIMENSTEIN, Gilberto; SAYAD, Alexandre Lê Voci, Colaborador. Aprendiz do Futuro: cidadania hoje e amanhã. 10.ed., São Paulo: Ática, 2005.

HOWARD, Robert; Et al. Aprendizado organizacional: gestão de pessoas para a inovação contínua. Rio de Janeiro: Campus, 2000.

LACOMBE, Francisco José Masset. Recursos humanos: princípios e tendências. 2. ed. São Paulo: SaraivaUni, 2006.

LIBANEO, José Carlos. Adeus professor, adeus professora? Novas exigências educacionais e profissão docente. 7. ed. São Paulo: Cortez, 2003 - (Coleção Questões de nossa época- número 67).

José Carlos. Didática. 1. ed. São Paulo: Cortez, 1994 - (Coleção magistério, 2 Grau. Série formação do professor). 
Artigo original

Hegemonia - Revista Eletrônica do Programa de Mestrado em Direitos Humanos, Cidadania e Violência/Ciência Política do Centro Universitário Unieuro

ISSN: 1809-1261

UNIEURO, Brasília, número 23, Janeiro a Junho de 2018, pp. 105-131.

José Carlos. Democratização da Escola Publica: A pedagogia críticosocial dos conteúdos. 21 ed. São Paulo: Edições Loyola, 2006 - (Coleção Educar - número 1)

MARRAS, Jean Pierre. Administração de recursos humanos: do operacional ao estratégico.

3. Ed. São Paulo: Futura, 2000.

OLIVEIRA, Pérsio Santos de. Introdução a Filosofia. 25. ed. São Paulo: Ática, 2004.

SHINYASHIKI, R. O sucesso é ser feliz. São Paulo: Gente, 1997.

TEDESCO, Juan Carlos (org.). Educação e Novas Tecnologias. São Paulo: Cortez; Buenos Aires: Instituto Internacional de Planeiamento de La Educacion; Brasília: UNESCO, 2004.

TOLEDO, Flavio de. O que são Recursos Humanos - 9. ed. São Paulo: Brasiliense, 2003 Coleção Primeiro Passos; 66. 